\title{
Binary Alignment Map
}

National Cancer Institute

\section{Source}

National Cancer Institute. Binary Alignment Map. NCI Thesaurus. Code C153249.

A binary representation of a sequence alignment map compressed by the BGZF library. 